\title{
From SARS to the Omicron variant of COVID-19: China's policy adjustments and changes to prevent and control infectious diseases
}

\author{
Mingyu Luo ${ }^{\S}$, Qinmei Liu ${ }^{\S}$, Jinna Wang ${ }^{\S}$, Zhenyu Gong* \\ Department of Communicable Disease Control and Prevention, Zhejiang Provincial Center for Disease Control and Prevention, Hangzhou, \\ Zhejiang, China.
}

SUMMARY The COVID-19 pandemic has been the biggest public health crisis in a century. Since it was initially reported in 2019, the duration and intensity of its impacts are still in serious question around the world, and it is about to enter its third year. The first public health revolution failed to achieve its ultimate targets, as previously contained infectious diseases seem to have returned, and new infectious diseases continue to emerge. The prevention and control of infectious diseases is still a public health priority worldwide. After SARS, China adjusted a series of its infectious disease policies. In order to ensure the effectiveness and implementation of prevention and control interventions, the government should integrate the concept of public health. Perhaps we need a global public health system at the government level to fight the potential threat of infectious disease. This system could include multifaceted strategies, not just specific prevention and control interventions, and it could also be a comprehensive system to ensure unimpeded communication and cooperation as well as sustainable development.

Keywords COVID-19, infectious disease, physical containment strategies, vaccination, global health, public health

The COVID-19 pandemic has been the biggest public health crisis in a century (Figure 1). According to the World Economic Outlook in April 2020, the International Monetary Fund ranked this crisis as the Great Lockdown. In addition to the public health crisis, this health emergency had triggered a global financial crisis, and containment measures have made stimulating aggregate activity more challenging (1). Worldwide, severe uncertainty about the duration and intensity of the pandemic's impacts remains in 2021, and a WHO Emergency Committee concluded that the pandemic is far from over. The Delta variant has become one of the most infectious viruses (R0:5-9·5) (2).

New strains pop up continuously. on Nov 26, 2021, WHO designated a new variant, Omicron. After its was first identified in southern Africa, Omicron has been found in 76 countries across the world as of Dec 14, 2021 (3). In the United States, 43 individuals infected with Omicron were identified from Dec. 1 to Dec. 8 (4); one individual was hospitalized but no deaths were reported. China has also identified 11 cases infected with Omicron until Dec. 15, 2021 (5.6). There is substantial uncertainty regarding Omicron's transmissibility and severity (7). The researchers from The University of Hong Kong found that Omicron SARS-CoV-2 infects and multiplies
70 times faster than the Delta variant and original SARSCoV-2 in human bronchus, but the infection in the lung is significantly lower than the original SARS-CoV-2 (8). Given the persistent mutation of the virus, if the SARS-CoV-2 virus becomes more transmissible and it continues to exist with human beings over the long time, then presumably the disease's severity will decrease and it will become "another type of influenza."

Omicron's immune escape potential is also uncertain. Breakthrough infections are likely to occur, which means relying more on physical containment strategies. The WHO also recommends that individuals socially distance and wear masks (7).

\section{China's experience and physical containment strategies.}

During the global fight against COVID-19, China has reported only $0.05 \%$ of the total number of global cases (more than 265 million) despite its huge population base. Unlike some Western countries, China mobilized quickly and coordinated a national campaign to contain outbreaks in Hubei and related epidemics (9.10). In about three months, China normalized prevention and control with a focus on imported cases and related outbreaks. Since 
Aug 2021, China has attempted to enter a new phase through a "dynamic zero tolerance" approach, which aims to formulate precise and differentiated strategies to prevent and control COVID-19 (Figure 2).

China's experience shows that physical containment strategies are not magic. Physical containment strategies that seek to interrupt the transmission of pathogens are effective at preventing and controlling COVID-19 and other infectious diseases (11). What is special is the implementation of these strategies. Traditional contact tracing and quarantine are always effective at identifying secondary cases and avoiding continued transmission. During outbreaks in Dalian (July 2020) and Guangzhou (May 2021), 74\% and 65\% of cases, respectively, were identified among close contacts (9). Implementation of social distancing and movement restrictions effectively

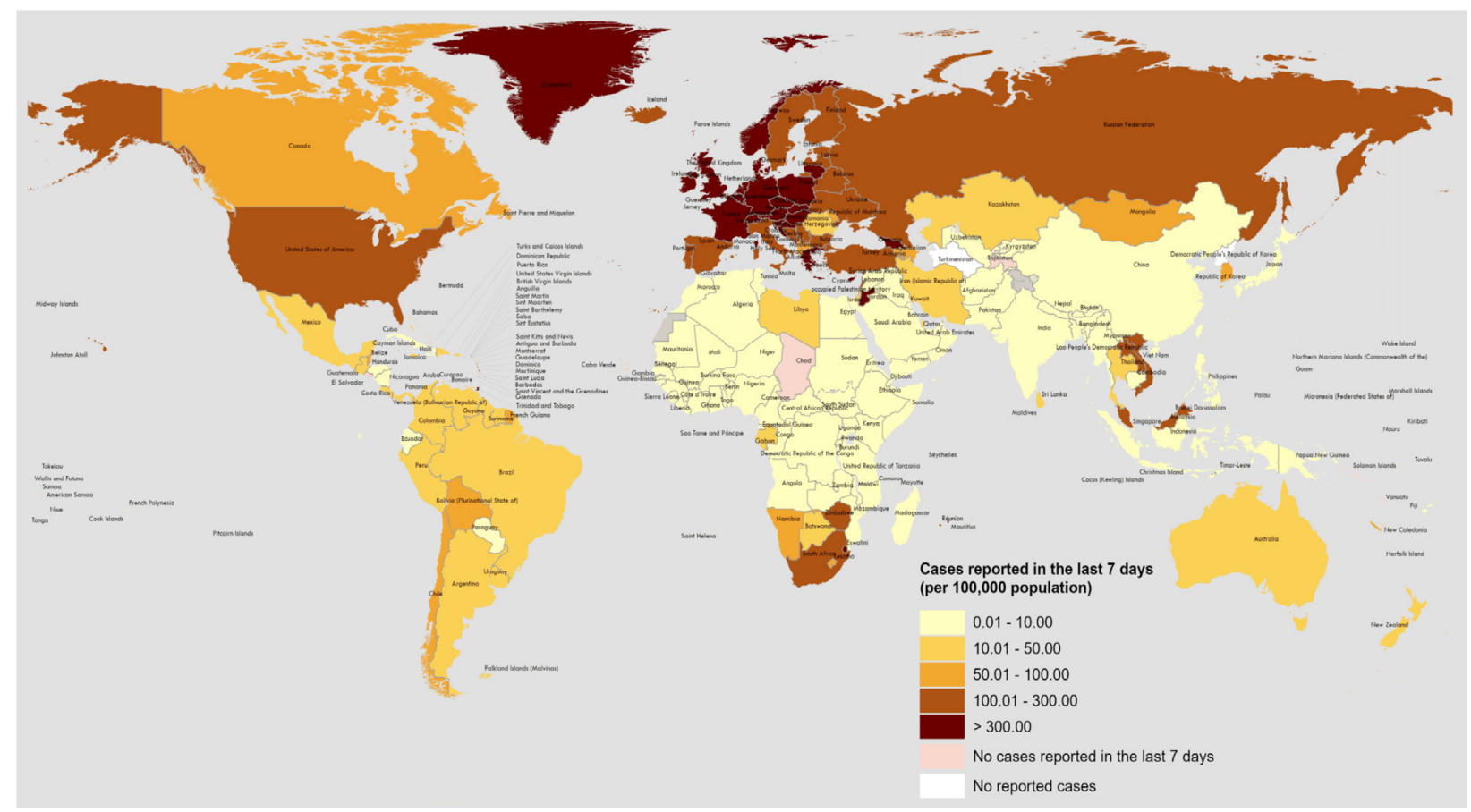

Figure 1. COVID-19 cases per 100,000 population reported by countries, territories, and areas, Dec-14 2021. Figures are from the COVID-19 Weekly Epidemiological Update. Data presented are based on official laboratory-confirmed COVID-19 cases and deaths reported to the WHO by country/territories/areas, largely based upon WHO case definitions and surveillance guidance.

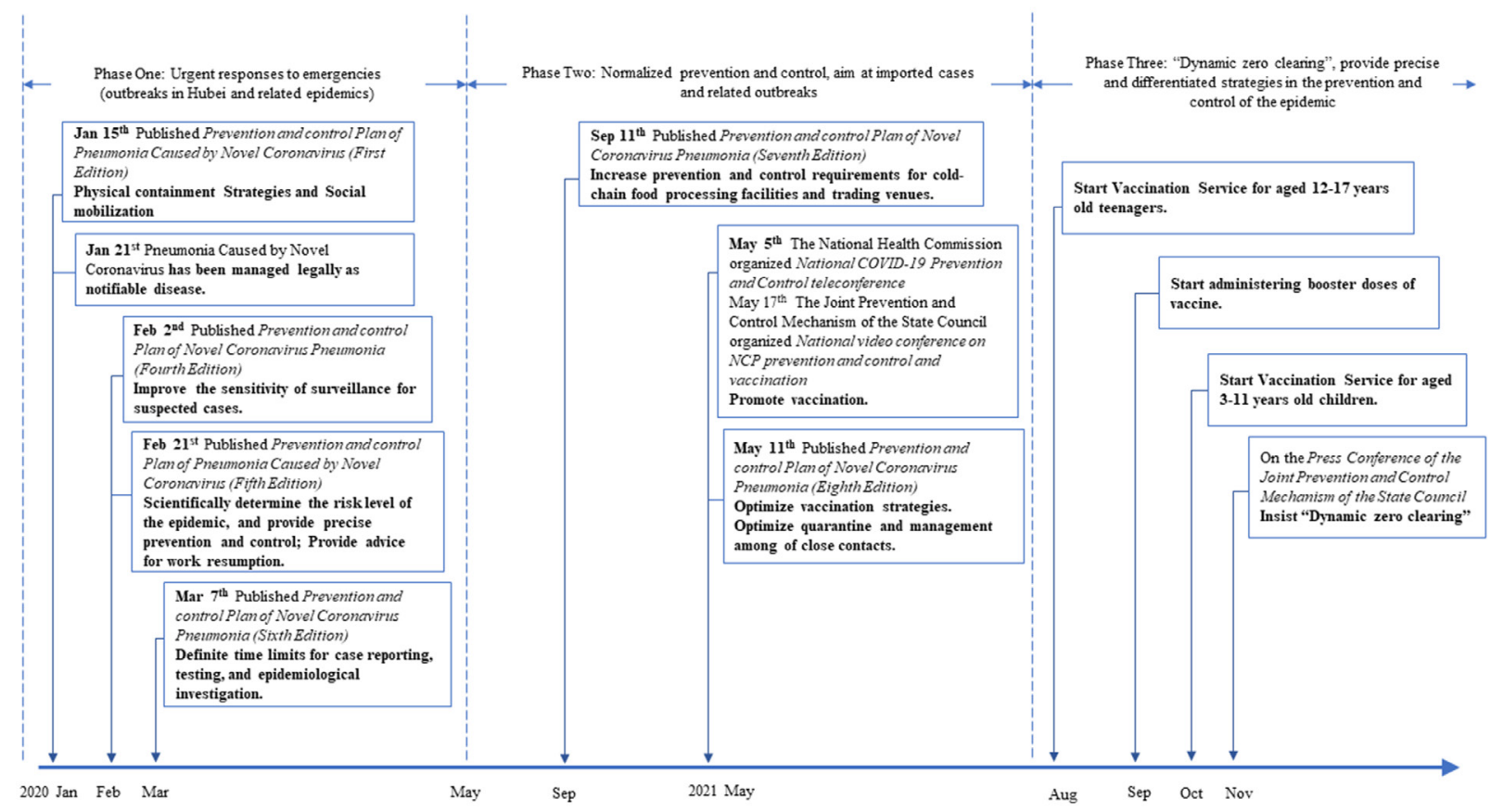

Figure 2 Prevention and control processes and strategies to combat COVID-19 in China since 2020. 
reduced the secondary attack rate among household contacts. During the Wuhan outbreak (from Dec 2019 to April 2020), the household reproduction number declined by $52 \%$ among primary cases and by $63 \%$ among secondary cases (12).

Containment interventions also mean a certain degree of infringement upon liberty. Policy-making needs to be based on scientific evidence to assure the legality of an intervention and to balance personal privacy and public health. Government also needs to support effective public mobilization and management. Thanks to rapid and sustained containment strategies, such as the lockdown in Wuhan, China avoided a 67 -fold increase in cases (interquartile range: 44-94-fold) within one month (13).

\section{Over the long term, prevention and control of infectious diseases is the basis of public health.}

The first public health revolution failed to achieve its ultimate targets, as previously contained infectious diseases seem to have returned, and new infectious diseases continue to emerge (emerging infectious diseases, or EIDs). In the late 20th century, most experts concurrently reached the conclusion that ideas on fitness and medical models should change and evolve. What causes the highest proportion of deaths has changed from acute infectious diseases to chronic diseases, and this is especially true in developed countries. However, outbreaks or pandemics of infectious diseases have presented a significant worldwide threat since 2000 . These diseases include reemerging diseases, such as HIV/AIDS, malaria, tuberculosis, and West Nile virus, as well as emerging ones, such as severe acute respiratory syndrome (SARS) and COVID-19. (Table 1) There are two types of infectious diseases that represent the greatest threat to public health worldwide. One is respiratory infectious disease; the other is vector-borne diseases.

\section{The concept of a global healthcare community should be integrated into all policies and regulations.}

Each epidemic or pandemic is the result of a complex interplay of natural evolution and human advancement. Many EIDs appear to be caused by zoonotic pathogens and involve interaction between humans and wildlife $(14,15)$. Paralleling natural evolution and human advancement, human activity seems to have expanded since mankind entered the 21 st century, increasing the probability of pandemics (14). In addition, climate change brought about by human activity may profoundly affect the transmission of pathogens and vectors $(16,17)$. Governments should once again acknowledge the actual and potential burden of infectious diseases.

Regrettably, global prevention and control efforts and awareness among the healthcare community worldwide have been far outpaced by the global spread of EIDs. Intervention strategies for infectious diseases and public health systems worldwide are not prepared for future challenges from EIDs. The WHO should expand its implementation and range of responsibilities by enhancing the "One Health" concept. A collaborative system should be created by health authorities and authorities related to wildlife and the environment. The relationship among human beings, other creatures, and diverse natural ecosystems should be fundamentally reconsidered, and the concept of global healthcare community should be devised.

Public health should be emphasized globally. In addition to development of effective vaccines in the near future, new International Health Regulations (IHR) (2022) may be modified and adopted, and a treaty or agreement with international support to fight infectious disease pandemics should also be concluded. Over the long term, political leadership at the global level is needed. The National Provider Identifier Standard (NPI) should be emphasized. Public health should be integrated into the United Nations' Sustainable Development Goals to be implemented by every member country and to facilitate global health initiatives.

Vaccines are the most crucial intervention to achieve herd immunity and prevent the spread of infectious disease. As a result of massive resources worldwide, COVID-19 vaccines have been rapidly developed in comparison to conventional vaccines. As the virus continues to mutate, research on new and highly effective vaccines should be accelerated. In the future, increased emphasis should be placed on biological research, and vaccine research and stockpiles should be improved to respond to the long-term challenges of EIDs.

To fight against potential infectious disease pandemics, training of public health personnel should be accelerated. In addition, leaders in global public health should be trained instead of relying on the CDC. There are many examples of exceptional teamwork in fighting pandemics: 1) The Epidemic Intelligence Service (EIS) of the US CDC has greatly contributed to the eradication of smallpox and many other immunization programs (18). 2) In 2003, Trainees from China's Field Epidemiology Training Programs helped provide scientific evidence for identification of and intervention in the SARS pandemic (19).

The COVID-19 pandemic has focused our attention on infectious diseases once again. We need to face the fact that the SARS-CoV-2 virus will coexist with human beings over the long term. As globalization continues, governments need to realize that the threat of infectious diseases is ever-present. We need to learn from past experience to build a global public health system to fight the potential threat of infectious diseases. This system should have multifaceted strategies and not just specific prevention and control interventions. It should also be a comprehensive system to ensure unimpeded 


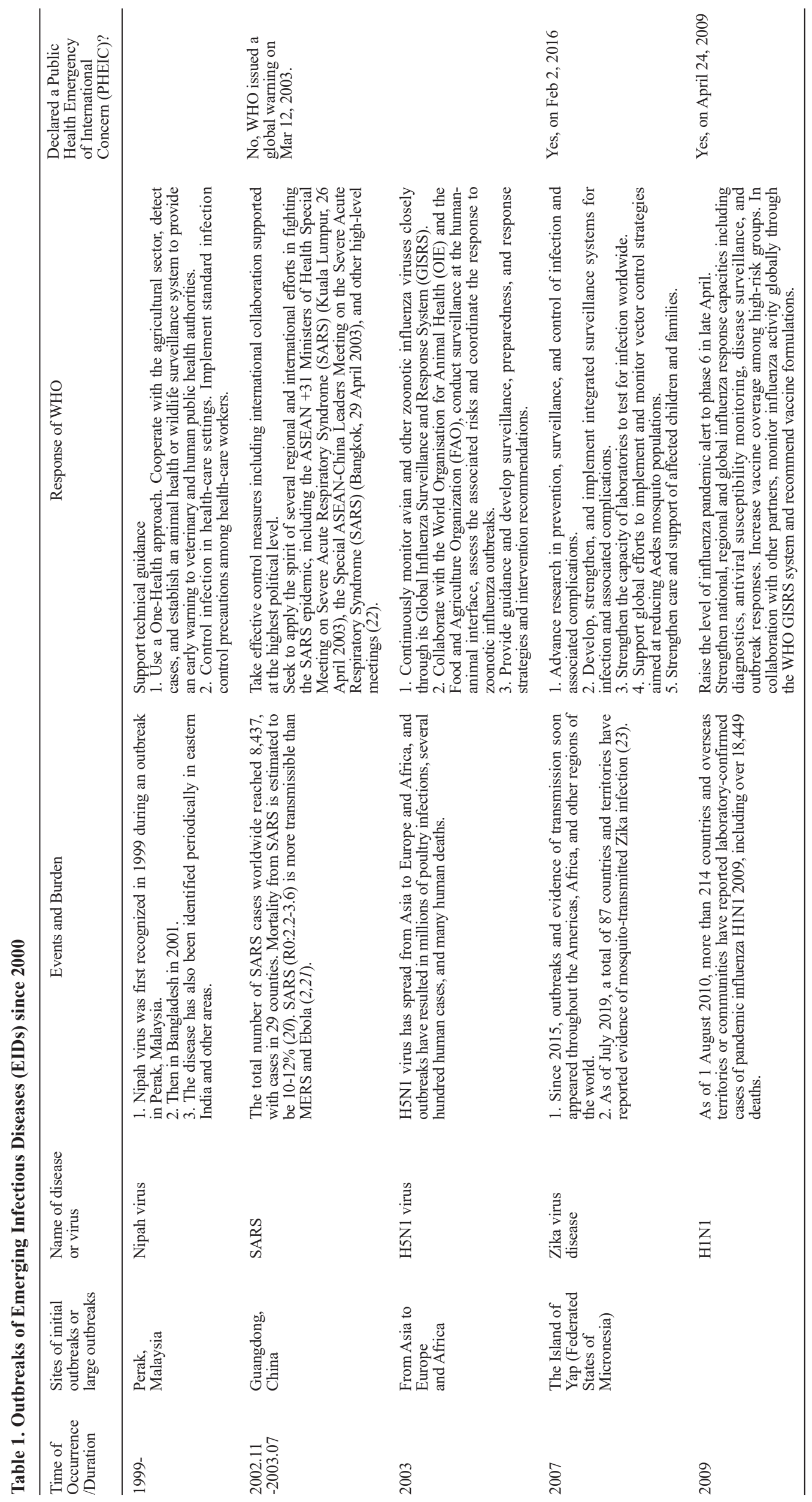




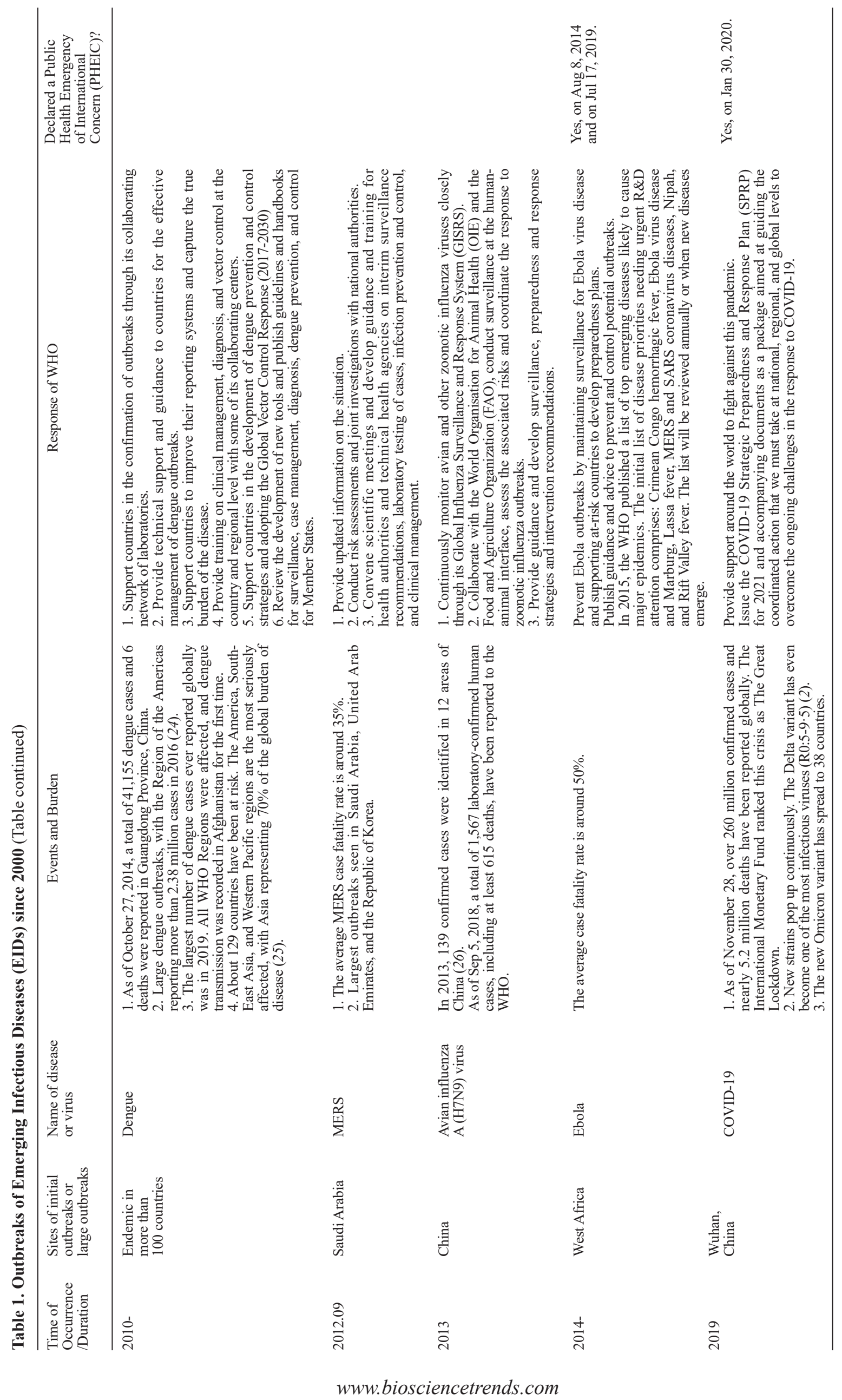


communication and cooperation as well as sustainable development.

Funding: This work was supported as a Major National Science and Technology Project in Infectious Diseases (grant no. 2017ZX10303404).

Conflict of Interest: The authors have no conflicts of interest to disclose.

\section{References}

1. International Monetary Fund. World Economic Outlook, April 2020: The Great Lockdown. https://www.imf.org/en/ Publications/WEO/Issues/2020/04/14/World-EconomicOutlook-April-2020-The-Great-Lockdown-49306 (accessed December 3, 2021).

2. McMorrow M. Improving communications around vaccine breakthrough and vaccine effectiveness. https:// context-cdn.washingtonpost.com/notes/prod/default/ documents/8a726408-07bd-46bd-a945-3af0ae 2f3c37/ note/57c98604-3b54-44f0-8b44-b148d8f75165 (accessed December 3, 2021).

3. WHO. COVID-19 Weekly Epidemiological Update. 2021. https://www.who.int/publications/m/item/covid-19-weeklyepidemiological-update (accessed December 14, 2021).

4. Variant S-BO, States U. SARS-CoV-2 B.1.1.529 (Omicron) Variant - United States, December 1-8, 2021. Morbidity and Mortality Weekly Report COVID-19. 2021; 70:1-5.

5. The Government of the Hong Kong Special Administrative Region. CHP investigates one additional confirmed case of COVID-19 and one additional Omicron case. $h t t p s: / / w w w$. info.gov.hk/gia/general/202112/15/P2021121500459. htm?fontSize $=1$ (accessed December 15, 2021).

6. The financial headlines of Sina.com. Tianjin, Guangzhou reported cases infected by Omicron; the first death from Omicron existed in the world. What are the challenges brought by the new strain? https://cj.sina.com.cn/ articles/view/2212518065/83e058b1019013fdj (accessed December 15, 2021). (in Chinese)

7. World Health Organization. Enhancing Readiness for Omicron (B.1.1.529): Technical Brief and Priority Actions for Member States. Vol 28. 2021.

8. The University of Hong Kong. HKUMed finds Omicron SARS-CoV-2 can infect faster and better than Delta in human bronchus but with less severe infection in lung. https://hku.hk/press/news_detail_23751.html (accessed December 15, 2021)

9. Chen Q, Rodewald L, Lai S, Gao GF. Rapid and sustained containment of COVID-19 is achievable and worthwhile: Implications for pandemic response. BMJ. 2021; 375:e066169.

10. Tang JL, Abbasi K. What can the world learn from China's response to COVID-19? BMJ. 2021; 375:n2806.

11. Luo M, Sun J, Gong Z, Wang Z. What is always necessary throughout efforts to prevent and control COVID-19 and other infectious diseases? A physical containment strategy and public mobilization and management. Biosci Trends. 2021; 15:188-191.

12. Li F, Li YY, Liu MJ, et al. Household transmission of SARS-CoV-2 and risk factors for susceptibility and infectivity in Wuhan: A retrospective observational study.
Lancet Infect Dis. 2021; 21:617-628.

13. Lai S, Ruktanonchai NW, Zhou L, et al. Effect of nonpharmaceutical interventions to contain COVID-19 in China. Nature. 2020; 585:410-413.

14. Daszak P, Cunningham AA, Hyatt AD. Emerging infectious diseases of wildlife - Threats to biodiversity and human health. Science. 2000; 287:443-449.

15. Huang Y, Xie J, Guo Y, Sun W, He Y, Liu K, Yan J, Tao A, Zhong N. SARS-CoV-2: origin, intermediate host and allergenicity features and hypotheses. Healthcare (Basel). 2021; 9:1132.

16. Altizer S, Ostfeld RS, Johnson PT, Kutz S, Harvell CD. Climate change and infectious diseases: From evidence to a predictive framework. Science. 2013; 341:514-519.

17. Baker-Austin C, Trinanes JA, Taylor NGH, Hartnell R, Siitonen A, Martinez-Urtaza J. Emerging Vibrio risk at high latitudes in response to ocean warming. Nat Clim Chang. 2013; 3:73-77.

18. Koplan J. CDC's strategic plan for bioterrorism preparedness and response. Public Health Rep. 2001; 116:9-16.

19. Guang Z. The glorious history of field epidemiology in China. Int J Epidemiol Infectious Dis. 2019; 46:335-339.

20. World Health Organization. SARS: Clinical trials on treatment using a combination of traditional Chinese medicine and Western medicine: Report of the WHO International Expert Meeting to review and analyse clinical reports on combination treatment for SARS, 8-10 October 2003, Beijing, People's Republic of China. (accessed December 3, 2021).

21. Lipsitch M, Cohen T, Cooper B, Robins JM, Ma S, James L, Gopalakrishna G, Chew SK, Tan CC, Samore MH, Fisman D, Murray M. Transmission dynamics and control of severe acute respiratory syndrome. Science. 2003; 300:1966-1970.

22. World Health Organization. Resolution of the World Health Assembly. Severe acute respiratory syndrome. In: Fifty-sixth World Health Assembly. 2003; WHA56.29. https://www.who.int/csr/sars/en/ea56r29.pdf (accessed December 3, 2021).

23. World Health Organization. Zika epidemiology update July 2019. https://www.who.int/publications/m/item/zikaepidemiology-update (accessed December 3, 2021).

24. Li LH, Zhang FC, Tang XP. The prevention and challenge of dengue fever. Zhi Hua Chuan Ran Bing Za Zhi. 2014; 32:760-762. (in Chinese)

25. Bhatt S, Gething PW, Brady OJ, et al. The global distribution and burden of dengue. Nature. 2013; 496:504507.

26. Li Q, Zhou L, Zhou M, et al. Epidemiology of human infections with avian influenza A(H7N9) virus in China. N Engl J Med. 2014; 370:520-532.

Received December 5, 2021; Revised December 16, 2021; Accepted December 17, 2021.

${ }^{\S}$ These authors contributed equally to this work.

*Address correspondence to:

Zhenyu Gong, Department of Communicable Disease Control and Prevention, Zhejiang Provincial Center for Disease Control and Prevention, Hangzhou 310051, Zhejiang, China.

E-mail: zhygong@cdc.zj.cn

Released online in J-STAGE as advance publication December 18, 2021. 